\title{
Editorial
}

\section{Platelets in Rheumatic Mitral Stenosis}

\author{
Jyotsna Maddury ${ }^{1}$ \\ ${ }^{1}$ Department of Cardiology, Nizam's Institute of Medical Sciences, \\ Hyderabad, India
}

Indian J Cardiovasc Dis Women-WINCARS 2018;3:213-214

Rheumatic mitral stenosis (MS) predisposes to thrombus formation in the left atrium (LA) and left atrial appendage (LAA) due to relative stagnation of blood as it finds difficulty to pass though the narrowed mitral orifice. There are studies on morphologic changes in platelets either as the cause or effect of MS in production of LA/LAA thrombus. In 2009, Varol et al and Yavuz et al showed that mean platelet volume (MPV) increased in MS even in sinus rhythm. ${ }^{1,2}$

Belen et al assumed rheumatic carditis-induced mitral valve disease to be a chronic inflammatory process. So they observed the platelet-to-lymphocyte ratio (PLR) in MS patients. ${ }^{3}$ In patients with LA thrombus, higher MPV and platelet count and lower lymphocyte count were detected. PLR was significantly higher in patients with thrombus than in those without $(133 \pm$ 38 vs. $119 \pm 31, p=0.001$ ).

Murugesen et al showed that the procoagulant condition (which means significant increase in fibrinogen, homocysteine, and platelet aggregation) was prevalent in subgroup of patient of MS with thrombus. ${ }^{4}$ Akpek et al showed that cheaper tests such as MPV and platelet crit are associated with thrombus in MS patient. ${ }^{5}$ Microparticle concentration increment that suggests that the platelet activation was shown in peripheral blood by Azzam and Zagloul. ${ }^{6}$

Hasan-Ali and Mosad and Erdogan et al demonstrated that not only there was an increase in inflammatory, platelet, thrombin, and fibrinolytic activities, but also that these parameters decreased after mitral valvotomy. ${ }^{7,8}$

In this issue Shravan et al also reported that morphologic changes in the platelets are more when there is thrombus in the LA/LAA. ${ }^{9}$ In addition to MPV, they studied platelet distribution width (PDW) also. Wider PDW means more abnormal-size platelets, either large or small size, may be there. However, PDW associated with increased MPV means that bigger size abnormal platelets are there in MS patients. This study may be important one as it was a pilot study on PDW in MS with thrombus. However, in this, the authors did not study whether these abnormally big platelets are functioning normally or abnormally.
I think further research on morphofunctional studies of platelets are required in these MS patients, as this increases the morbidity by 10 -fold in thromboembolic risk.

\section{Conflict of Interest}

None.

\section{References}

1 Varol E, Ozaydin M, Türker Y, Alaca S. Mean platelet volume, an indicator of platelet activation, is increased in patients with mitral stenosis and sinus rhythm. Scand J Clin Lab Invest 2009;69(6):708-712

2 Yavuz B, Ertugrul DT, Yalcin AA, Kucukazman M, Ata N, Dal K. Increased mean platelet volume in rheumatic mitral stenosis: a possible factor for thromboembolic events. J Cardiol 2009;53(2):204-207

3 Belen E, Özal E, Püsüroğlu H. Relationship between the presence of left atrial thrombus in patients with mitral stenosis and platelet-to-lymphocyte ratio. Anatol J Cardiol 2016 Sep;16(9):673-677

4 Murugesan V, Pulimamidi VK, Rajappa M, Satheesh S, Revathy G, Harichandrakumari KT. Elevated fibrinogen and lowered homocysteine-vitamin determinants and their association with left atrial thrombus in patients with rheumatic mitral stenosis. Br J Biomed Sci 2015;72(3):102-106

5 Akpek M, Kaya MG, Yarlioglues M, et al. Relationship between platelet indices and spontaneous echo contrast in patients with mitral stenosis. Eur J Echocardiogr 2011;12(11):865-870

6 Azzam H, Zagloul M. Elevated platelet microparticle levels in valvular atrial fibrillation. Hematology 2009;14(6):357-360

7 Hasan-Ali H, Mosad E. Changes in platelet, coagulation, and fibrinolytic activities in mitral stenosis after percutaneous mitral valvotomy: role of hemodynamic changes and systemic inflammation. Clin Appl Thromb Hemost 2015;21(4):339-347

8 Erdogan D, Icli A, Aksoy F, et al. Percutaneous mitral balloon valvuloplasty reduces mean platelet volume in patients with rheumatic mitral stenosis. Scand J Clin Lab Invest 2012;72(6):452-458

9 Kumar SCH, Kalivela S, Yerra S, Garre I, Kumar A. Role of platelets in rheumatic mitral stenosis patients: an observational study. IJCDW 2018;3(4)

\footnotetext{
Address for correspondence Jyotsna Maddury, MD, DM, FACC, FESC, FICC, Department of Cardiology, Nizam's Institute of Medical Sciences, Punjagutta 500082, Hyderabad, Telangana, India (e-mail: mail2jyotsna@rediffmail.com).
}

DOI https://doi.org/ 10.1055/s-0039-1681123
(C)2018 Women in Cardiology and Related Sciences

\section{License terms}

$($ () (1) $\ominus \circledast$ 
